\title{
Reasonable Figure of Subsonic Train Front and Rear in Evacuated Tube Transportation Based on Aerodynamics Consideration
}

\author{
Yaoping ZHANG ${ }^{1, a}$, Jun $\mathrm{ZHU}^{2, \mathrm{~b}}$, Baigang $\mathrm{MI}^{2}$ and Maoxing SHEN ${ }^{1}$ \\ ${ }^{1}$ Institute of Evacuated Tube Transportation, Xijing University, Xi'an 710123, China \\ ${ }^{2}$ School of Aeronautics, Northwestern Polytechnical University, Xi'an 710072, China \\ atubetrans@hotmail.com, b13233093@qq.com
}

Keywords: Subsonic train; Taper Front; Evacuated Tube Transportation; Partial vacuum;
Aerodynamics drag

\begin{abstract}
Based on hypothesis of incompressible viscous flow, 2D stable flow field and moving tube wall conditions, as well as Navier-Stokes equation and $k$ - $\varepsilon$ two-equation turbulent models, the aerodynamic drag imposed on the trains with different front/rear shapes which run at subsonic speed in evacuated tubes were calculated respectively. By analyzing the calculating results, it could be found that the streamlined train front/rear are effective for reducing aerodynamic drag acted on ETT trains running at subsonic speed and in partial vacuum tube from $101.25 \sim 10132.5 \mathrm{~Pa}$, and it is apparently more effective for reducing aerodynamic drag acted on trains in the tube to attach both taper front and rear than only taper front. The optimized taper length of the ETT train front/rear is 1.5 2 times of the train body section diameter. In addition, pointed out that a vertically symmetric taper is right for the ETT train front/rear.
\end{abstract}

\section{Introduction}

Evacuated Tube Transportation (ETT) will be the fastest traffic mode on earth in the future, possible over $6000 \mathrm{~km} / \mathrm{h}$, and low energy consumption, no air pollution, no noise and relatively safer [1-5]. However, ETT trains would run only at a subsonic speed $500 \sim 1000 \mathrm{~km} / \mathrm{h}$ on its primary stage, and the relating reasonable partial vacuum in the tube would be $101.325 \sim 10132.5 \mathrm{~Pa}$ [6]. In such a partial vacuum tube, a streamlined front/rear of the ETT train is also needed. A question is that what a kind of streamlined front/rear would be better.

With FLUENT 6.3 software package, based on the hypothesis of incompressible viscous flow, two dimensional stable flow field, as well as Navier-Stokes equation and $k$ - $\varepsilon$ two-equation turbulent models, this paper calculates aerodynamic drag imposed on ETT trains with different fronts and rears running at different vacuum degree. By comparing the aerodynamic drag value of various train figures, some suggestions on the reasonable ETT train front/rear design are put up.

\section{Calculating conditions}

\section{Basic hypothesis}

Supposing the gas in ETT tube is incompressible, viscous, 2D flow field and stable flow; supposing the gas density accords with standard gas state equation $p=\rho R T$. This paper calculates the relative aerodynamic drag only when the gas pressure $p$ is 1013.25 and $101.325 \mathrm{~Pa}$ (namely the relevant gas density $\rho$ is 0.01225 and $0.001225 \mathrm{~kg} / \mathrm{m}^{3}$ ).

The flow field Renault number $R_{e}$ is as following [7-9]: $R_{e}=\frac{\rho V L}{\mu}$. Here the speed $V=[100,300]$ $(\mathrm{m} / \mathrm{s})$, the characteristic length $L=3 \mathrm{~m}$, viscous coefficient $\mu=1.7894\left(10^{-5} \mathrm{~kg} / \mathrm{m}-\mathrm{s}\right)$ [8-9], then $\min R_{e}=\frac{\min \{\rho V L\}}{\max \{\mu\}}=\frac{0.001225 \times 9.8 \times 100 \times 3}{1.7894 \times 10^{-5}}=201270$. The minimum $R_{e}$ number is much more than 2000 , thus the flow field should be coped as turbulent flow.

\section{Geometry model}


The geometry models used for calculating the aerodynamic drag are as shown in Fig. 1. In these models, the ETT trains are columned, diameter $d_{v}=2 \mathrm{~m}$, body length $16 \mathrm{~m}$. Some models with blunt rear but streamlined fronts length $0 d_{v} \sim 2.5 d_{v}$ (see Fig. 1a), other models with both streamlined fronts and streamlined rears length $0 d_{v} \sim 2.5 d_{v}$ (see Fig. 1b). The distance from the train front to the inlet is $60 \mathrm{~m}$; the distance from the train trail to outlet also is $60 \mathrm{~m}$. The tube inside diameter $d_{t}$ used for calculating the aerodynamic drag is $3 \mathrm{~m}$, and that the calculation flow field area is $136 \mathrm{~m}$.

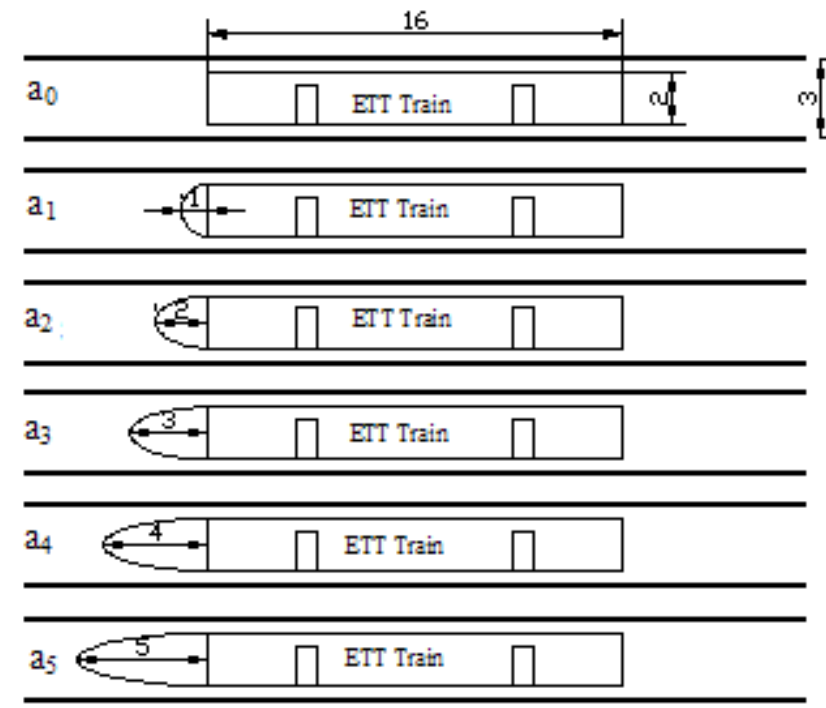

a. Trains with only taper front

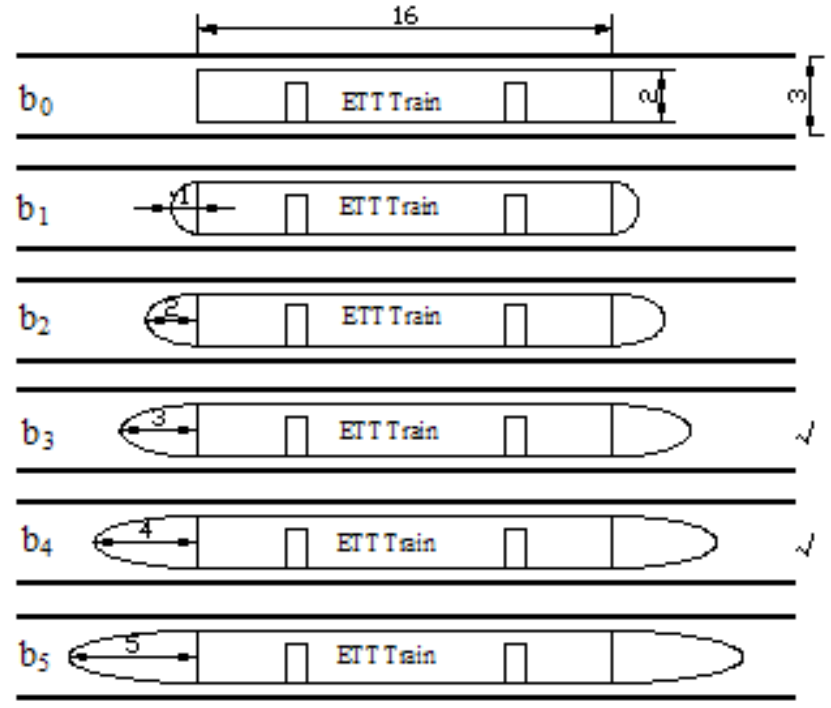

b. Trains with both taper front and taper rear

Fig. 1 ETT trains with various front/rear

The geometry models in this paper are axis symmetry structure. In order to simplify the calculation and accelerate convergence, a half flow field calculation region is considered. A sketch of one among model grid meshings is shown in Fig. 2a. A 3d sketch of the model is shown as Fig. $2 b$.

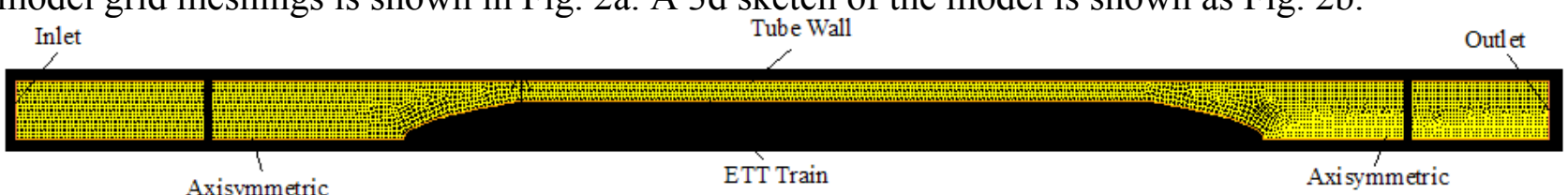

a. Calculation flow field area and meshing

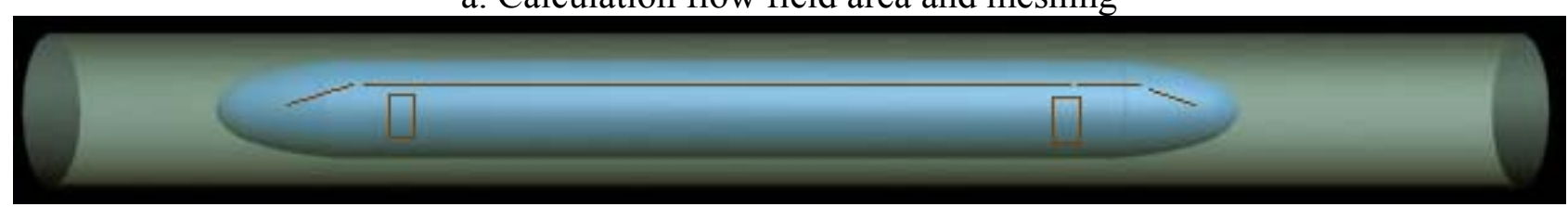

b. $3 \mathrm{~d}$ sketch of ETT train in the tube

Fig. 2 Geometry models for calculating aerodynamic drag

The main solver settings in FLUENT 6.3 are listed as follow: Solver->pressure based; Viscous Model->k- epsilon (2 eqn); Inlet-> Velocity-inlet; Outlet-> Outflow; Tube wall->Moving.

\section{Calculating and analyzing}

\section{Aerodynamic drag $F_{D}$ acted on the train when the partial vacuum is 1013.25Pa}

For the partial vacuum 1013.25Pa, different ETT train fronts with streamlined length $0 d_{v}, 0.5 d_{v}$, $1.0 d_{v}, 1.5 d_{v}, 1.75 d_{v}, 2 d_{v}, 2.5 d_{v}$ (namely here $0 \mathrm{~m}, 1 \mathrm{~m}, 2 \mathrm{~m}, 3 \mathrm{~m}, 3.5 \mathrm{~m}, 4 \mathrm{~m}, 5 \mathrm{~m}$ ) where $d_{v}$ is the train body diameter, but rears blunt (see Fig. 1a), aerodynamic drag $F_{D}$ at subsonic from $100 \mathrm{~m} / \mathrm{s}$ to $300 \mathrm{~m} / \mathrm{s}$ are respectively calculated as shown in Table 1 . Furthermore, a figure with the abscissa taper length and the y-axis aerodynamic drag is drawn as shown in Fig. 3a. It could be found that a taper front is quite effective for reducing aerodynamic drag acted on ETT train, for example, the total aerodynamic drag acted on a train with blunt front and blunt rear (the taper length $0 \mathrm{~m}$ ) is $7.909 \mathrm{kN}$ at speed $300 \mathrm{~m} / \mathrm{s}$, but the drag is reduced to $4.706 \mathrm{kN}$ when a taper front is attached. 
Table 1 Aerodynamic drag $F_{D}$ acted on trains with only taper front running in ETT tube (Unit: $\mathrm{kN}$ )

\begin{tabular}{|c|c|c|c|c|c|c|c|}
\hline Front Length & $\begin{array}{c}0 d \\
(0 \mathrm{~m})\end{array}$ & $\begin{array}{c}0.5 d \\
(1 \mathrm{~m})\end{array}$ & $\begin{array}{c}1.0 d \\
(2 \mathrm{~m})\end{array}$ & $\begin{array}{c}1.5 d \\
(3 \mathrm{~m})\end{array}$ & $\begin{array}{c}1.75 d \\
(3.5 \mathrm{~m})\end{array}$ & $\begin{array}{c}2 d \\
(4 \mathrm{~m})\end{array}$ & $\begin{array}{c}2.5 d \\
(5 \mathrm{~m})\end{array}$ \\
\hline Speed $(\mathrm{m} / \mathrm{s})$ & 0.923 & 0.566 & 0.535 & 0.521 & 0.517 & 0.521 & 0.517 \\
\hline 100 & 2.035 & 1.234 & 1.223 & 1.135 & 1.127 & 1.135 & 1.126 \\
\hline 200 & 3.573 & 2.149 & 2.182 & 1.977 & 1.964 & 1.977 & 1.960 \\
\hline 250 & 5.531 & 3.307 & 3.408 & 3.043 & 3.022 & 3.043 & 3.016 \\
\hline 300 & 7.909 & 4.706 & 4.901 & 4.330 & 4.302 & 4.331 & 4.292 \\
\hline
\end{tabular}

Also the partial vacuum 1013.25Pa, different ETT train both fronts and rears with streamlined length $0 d_{v}, 0.5 d_{v}, 1.0 d_{v}, 1.5 d_{v}, 1.75 d_{v}, 2 d_{v}, 2.5 d_{v}$ (see Fig. 1b), aerodynamic drag $F_{D}$ at subsonic from $100 \mathrm{~m} / \mathrm{s}$ to $300 \mathrm{~m} / \mathrm{s}$ are respectively calculated as shown in Table 2 . Furthermore, a figure is also drawn as shown in Fig. 3b. It could be found that a vehicle figure with both the taper front and taper rear is better than only a taper front for reducing aerodynamic drag, for example, the total aerodynamic drag acted on a train with only a taper front (the taper length $3 \mathrm{~m}$ ) is $4.33 \mathrm{kN}$ at speed $300 \mathrm{~m} / \mathrm{s}$ (see Table 1), but the drag is reduced to $1.872 \mathrm{kN}$ at the same speed when a taper rear is attached (see Table 2 and Fig. 3b). In addition, we also could find that it isn't apparently effective for reducing the aerodynamic drag to further extend the taper length after $1.5 d_{v}$. Therefore, the reasonable taper length of ETT front/rear should be $1.5 \sim 2 d_{v}$ as shown in Fig. 1 b- $b_{3}$ and $b_{4}$.

Table 2 Aerodynamic drag $F_{D}$ acted on trains with both taper front and taper rear running in ETT tube (Unit: $\mathrm{kN}$ )

\begin{tabular}{|c|c|c|c|c|c|c|c|}
\hline Front/Rear Length & $\begin{array}{c}0 d \\
(0 \mathrm{~m})\end{array}$ & $\begin{array}{c}0.5 d \\
(1 \mathrm{~m})\end{array}$ & $\begin{array}{c}1.0 d \\
(2 \mathrm{~m})\end{array}$ & $\begin{array}{c}1.5 d \\
(3 \mathrm{~m})\end{array}$ & $\begin{array}{c}1.75 d \\
(3.5 \mathrm{~m})\end{array}$ & $\begin{array}{c}2 d \\
(4 \mathrm{~m})\end{array}$ & $\begin{array}{c}2.5 d \\
(5 \mathrm{~m})\end{array}$ \\
Speed(m/s) & 0.923 & 0.329 & 0.276 & 0.250 & 0.244 & 0.240 & 0.239 \\
\hline 100 & 2.035 & 0.702 & 0.584 & 0.525 & 0.509 & 0.500 & 0.498 \\
\hline 150 & 3.573 & 1.202 & 0.993 & 0.888 & 0.862 & 0.845 & 0.840 \\
\hline 200 & 5.531 & 1.822 & 1.505 & 1.339 & 1.296 & 1.270 & 1.261 \\
\hline 250 & 7.909 & 2.571 & 2.113 & 1.872 & 1.811 & 1.772 & 1.757 \\
\hline 300 & \multicolumn{1}{|r}{}
\end{tabular}

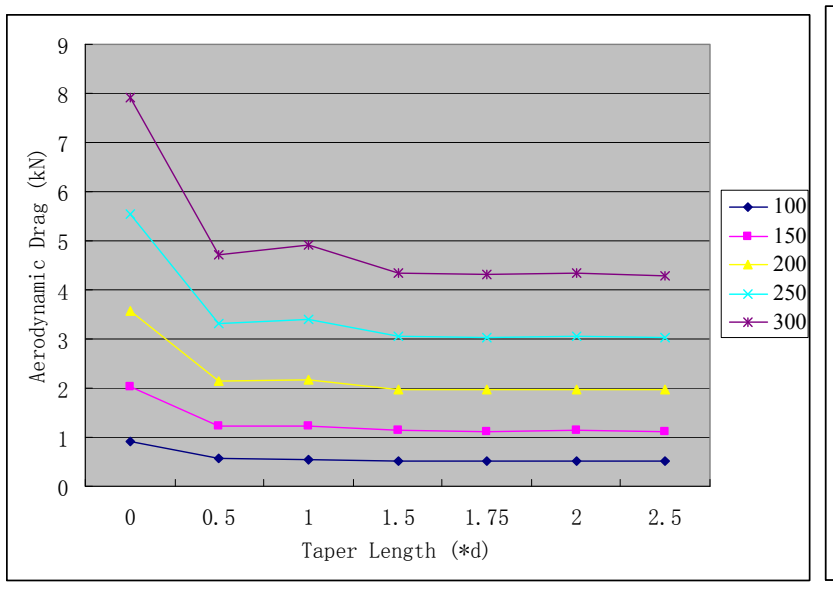

a. Where trains with only taper fronts

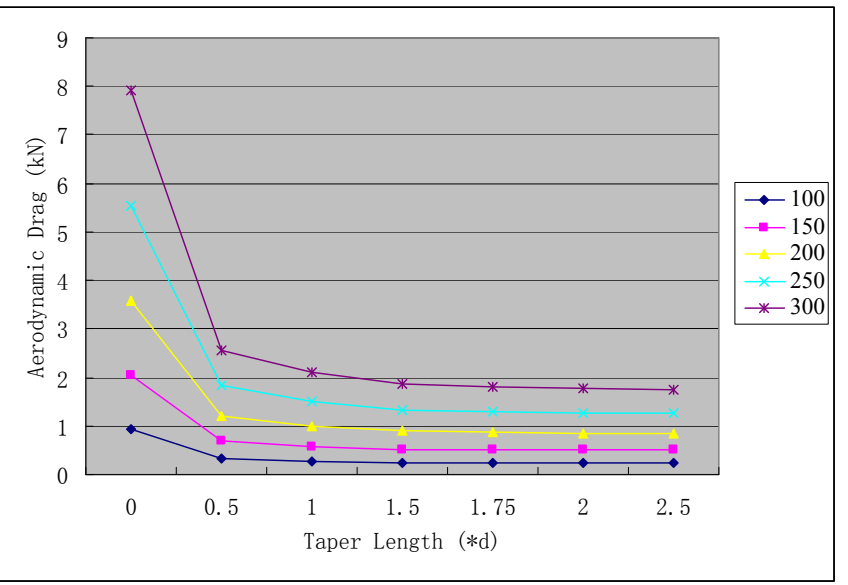

b. Where trains with both taper fronts and rears

Fig. 3 Relationship figure between the taper length of train front/rear and aerodynamic drag at $1013.25 \mathrm{~Pa}$

\section{Aerodynamic drag $F_{D}$ acted on the train when the partial vacuum is $1 / 1000$ atm}

For the partial vacuum $101.325 \mathrm{~Pa}$, and different ETT train fronts with streamlined length $0 d v$, $0.5 d_{v}, 1.0 d_{v}, 1.5 d_{v}, 1.75 d_{v}, 2 d_{v}, 2.5 d_{v}$, but rears blunt (see Fig. 1a), aerodynamic drag $F_{D}$ at subsonic from $100 \mathrm{~m} / \mathrm{s}$ to $300 \mathrm{~m} / \mathrm{s}$ are respectively calculated as shown in Table 3 . And, a figure with the abscissa taper length and the $y$-axis aerodynamic drag is drawn as shown in Fig. 4a. Again it is found that a taper front is quite effective for reducing aerodynamic drag acted on ETT train. For example, the total aerodynamic drag acted on a train with blunt front and blunt rear (the taper length $0 \mathrm{~m}$ ) is $0.872 \mathrm{kN}$ at speed $300 \mathrm{~m} / \mathrm{s}$, but the drag is reduced to $0.521 \mathrm{kN}$ when a taper front is attached. 
Table 3 Aerodynamic drag $F_{D}$ acted on the train with only taper front running in ETT tube (Unit: kN)

\begin{tabular}{|c|c|c|c|c|c|c|c|}
\hline Front Length & $\begin{array}{c}0 d \\
(0 \mathrm{~m})\end{array}$ & $\begin{array}{c}0.5 d \\
(1 \mathrm{~m})\end{array}$ & $\begin{array}{c}1.0 d \\
(2 \mathrm{~m})\end{array}$ & $\begin{array}{c}1.5 d \\
(3 \mathrm{~m})\end{array}$ & $\begin{array}{c}1.75 d \\
(3.5 \mathrm{~m})\end{array}$ & $\begin{array}{c}2 d \\
(4 \mathrm{~m})\end{array}$ & $\begin{array}{c}2.5 d \\
(5 \mathrm{~m})\end{array}$ \\
\hline Speed(m/s) & 0.106 & 0.071 & 0.067 & 0.066 & 0.066 & 0.066 & 0.066 \\
\hline 100 & 0.229 & 0.151 & 0.144 & 0.141 & 0.141 & 0.142 & 0.141 \\
\hline 150 & 0.399 & 0.259 & 0.247 & 0.242 & 0.241 & 0.243 & 0.242 \\
\hline 200 & 0.613 & 0.395 & 0.377 & 0.369 & 0.367 & 0.370 & 0.368 \\
\hline 300 & 0.872 & 0.558 & 0.533 & 0.521 & 0.519 & 0.522 & 0.520 \\
\hline
\end{tabular}

Also the partial vacuum $101.325 \mathrm{~Pa}$, different ETT train fronts and rears with taper length $0 d v$, $0.5 d_{v}, 1.0 d_{v}, 1.5 d_{v}, 1.75 d_{v}, 2 d_{v}, 2.5 d_{v}$ (see Fig. 1b), aerodynamic drag $F_{D}$ at subsonic from $100 \mathrm{~m} / \mathrm{s}$ to $300 \mathrm{~m} / \mathrm{s}$ are respectively calculated as shown in Table 4 . A figure is also drawn as shown in Fig. 4b. Again it is found that a vehicle figure with both the taper front and taper rear is better than only a taper front for reducing aerodynamic drag. For example, the total aerodynamic drag acted on a train with only a taper front (the taper length $3 \mathrm{~m}$ ) is $0.521 \mathrm{kN}$ at speed $300 \mathrm{~m} / \mathrm{s}$ (see Table 3 ), but the drag is reduced to $0.281 \mathrm{kN}$ when a taper rear is attached (see Table 4 and Fig. $4 \mathrm{~b}$ ). In addition, again we find that it isn't effective for reducing the aerodynamic drag to further extend the taper length after $1.5 d_{v}$. Then we can further get the conclusion that the reasonable taper length of ETT front/rear should be $1.5 \sim 2 d_{v}$ (see Fig. $1 \mathrm{~b}-\mathrm{b}_{3}$ and $\mathrm{b}_{4}$ ).

Table 4 Aerodynamic drag $F_{D}$ acted on the train with both taper front and taper rear running in ETT tube

\begin{tabular}{|c|c|c|c|c|c|c|c|}
\hline \multicolumn{2}{|c|}{ (Unit: $\mathrm{kN})$} \\
Front/Rear Length & $\begin{array}{c}0 d \\
(0 \mathrm{~m})\end{array}$ & $\begin{array}{c}0.5 d \\
(1 \mathrm{~m})\end{array}$ & $\begin{array}{c}1.0 d \\
(2 \mathrm{~m})\end{array}$ & $\begin{array}{c}1.5 d \\
(3 \mathrm{~m})\end{array}$ & $\begin{array}{c}1.75 d \\
(3.5 \mathrm{~m})\end{array}$ & $\begin{array}{c}2 d \\
(4 \mathrm{~m})\end{array}$ & $\begin{array}{c}2.5 d \\
(5 \mathrm{~m})\end{array}$ \\
\hline 100 & 0.106 & 0.048 & 0.042 & 0.040 & 0.040 & 0.039 & 0.040 \\
\hline 150 & 0.229 & 0.099 & 0.087 & 0.082 & 0.081 & 0.080 & 0.081 \\
\hline 200 & 0.399 & 0.166 & 0.145 & 0.136 & 0.134 & 0.133 & 0.134 \\
\hline 250 & 0.613 & 0.249 & 0.217 & 0.203 & 0.200 & 0.197 & 0.199 \\
\hline 300 & 0.872 & 0.348 & 0.302 & 0.281 & 0.276 & 0.273 & 0.274 \\
\hline
\end{tabular}

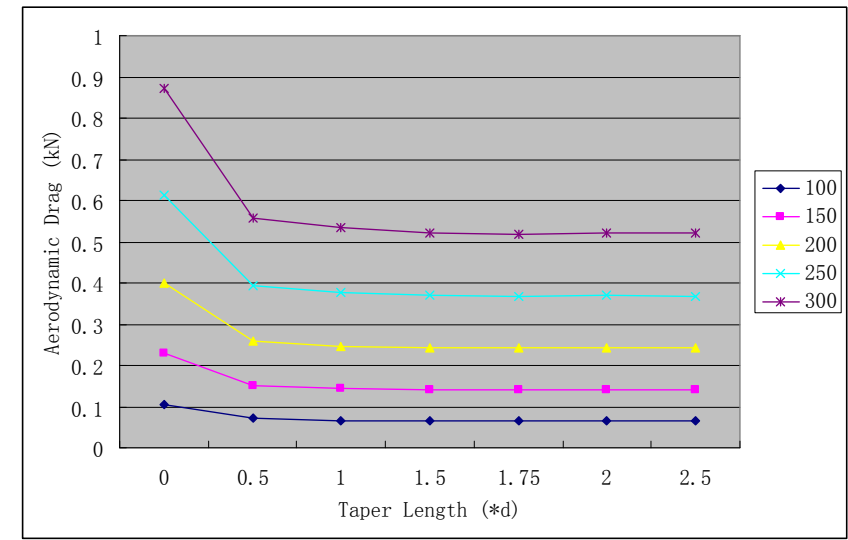

a. Where trains with only taper fronts

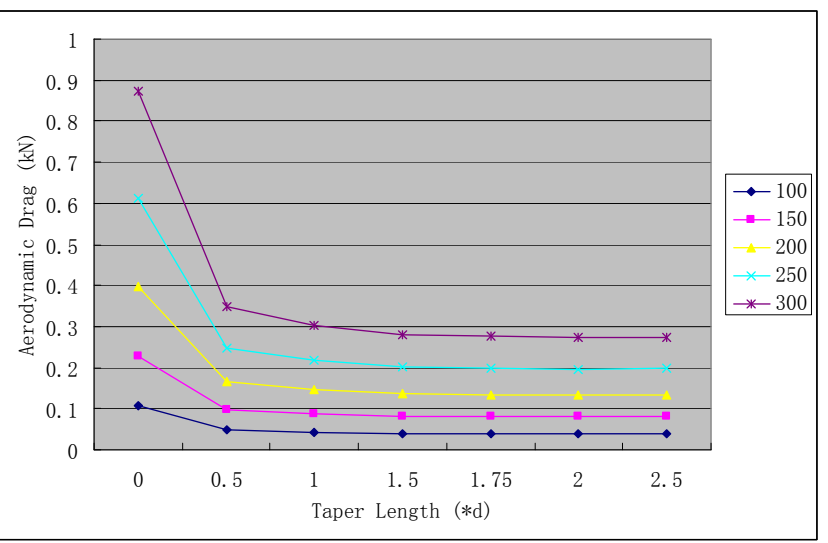

b. Where trains with both taper fronts and rears

Fig. 4 Relationship figure between the taper length of train front/rear and aerodynamic drag at $101.325 \mathrm{~Pa}$

Comparing the results in Table 1, Table 2 and Fig. 3 with the results in Table 3, Table 4 and Fig. 4, it is clear that it is especially effective for reducing aerodynamic drag to reduce the gas pressure in the tube. For example, the drag on ETT train with blunt front $/$ rear is $7.909 \mathrm{kN}$ at speed $300 \mathrm{~m} / \mathrm{s}$ when the pressure in tube is $1013.25 \mathrm{~Pa}$, but the drag with same other conditions is $0.872 \mathrm{kN}$ when the pressure in tube is reduced to $101.325 \mathrm{~Pa}$. In some cases, the drag $0.872 \mathrm{kN}$ would be an acceptable value for a train. Therefore, ETT train with the blunt front/rear would be a possible option when the gas pressure in the tube is less than $101.325 \mathrm{~Pa}$ and the speed is subsonic. 
For common trains or high-speed trains running in open surroundings, the aerodynamic pressure in the vertical direction $q_{b}$ ( $\uparrow$ upwards at the bottom of the train body) is always more than the gas pressure at the top of the train body ( $\downarrow$ updown). In order to reduce the total aerodynamic lifting force acted on the train body which is harmful for the train safety, the train front/rears are generally designed into the ramp shape as shown in Fig. 5, not symmetric in the vertical direction. However, it should be noticed that for an ETT train in a closed tube, the aerodynamic pressure $q_{b}$ at the train bottom is about equal to the aerodynamic pressure $q_{a}$ at the train top, namely the aerodynamic lifting force is about 0 . Thus the ramp front/rear for reducing aerodynamic lifting force is not necessary and the vertically symmetric taper front/rare (see Fig. 6) are right for ETT trains. In order to get an aerodynamic lifting force more than zero, the front/rear shape as shown in Fig. 7 (reverse to that of a high-speed train) may be an option for the ETT train.

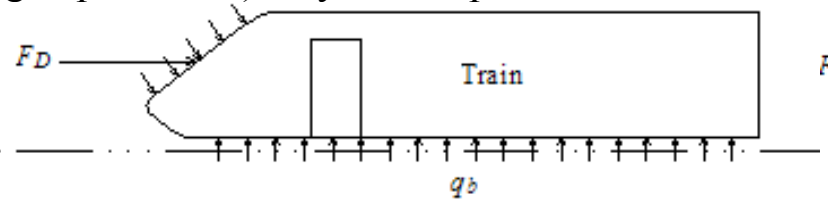

a.

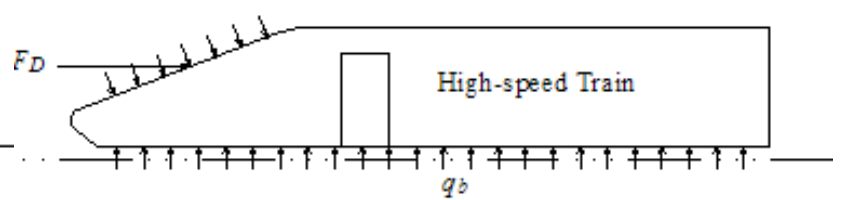

b.

Fig. 5 Ramp train front/rear

qa

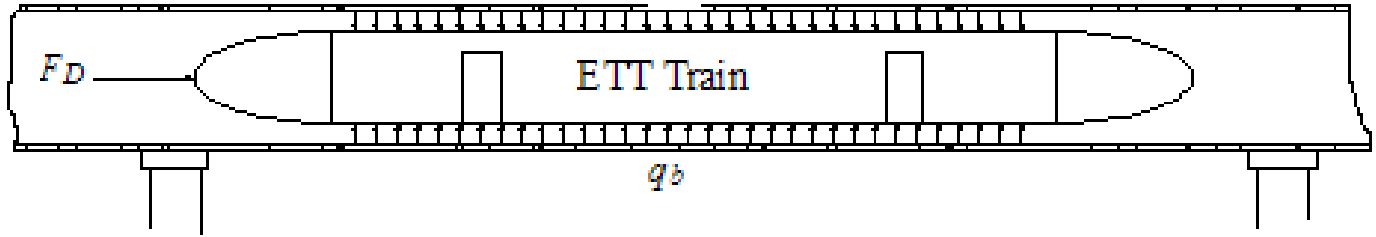

Fig. 6 ETT train with the vertically symmetric front/rear

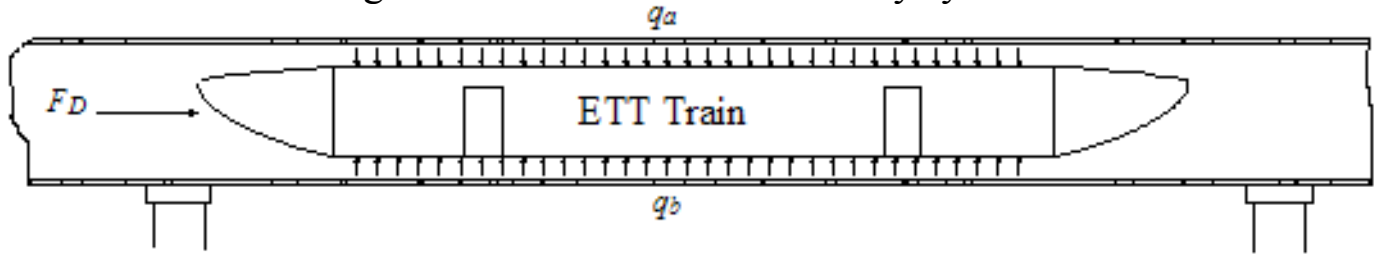

Fig. 7 ETT train with the vertically nonsymmetrical front/rear

\section{Conclusions}

By the above calculating and analyzing, some conclusions are got as follow:

When the vacuum in ETT tube is low, e.g. the gas pressure in that is high, for example, $1013.25 \mathrm{~Pa}$ or $101.325 \mathrm{~Pa}$, the aerodynamic drag acted on ETT trains running in ETT tube is high, and a streamlined front/rear could apparently reduce the aerodynamic drag. And, the total aerodynamic drag acted on ETT train with both streamlined front and rear is apparently less than that on ETT train with only streamlined front. Therefore, both streamlined front and rear are necessary for an ETT train running in ETT tube when the gas pressure in the tube is high, such as more than 101.325Pa.

The optimized taper length of the ETT train front/rear is about 1.5 2 times of the diameter of the ETT train body, no necessary too long.

When the gas pressure in the tube is low enough, such as less than $101.325 \mathrm{~Pa}$, the blunt front/rear would be a possible option for the subsonic ETT trains in some cases.

The right front/rear of ETT trains are vertically symmetric, not like the ramp front/rear of high-speed trains. If necessary, the vertically nonsymmetrical front/rear may be considered for ETT trains which is reverse to the ramp direction of the current high-speed train fronts.

\section{References}

[1] Zhang Yaoping, Daryl Oster. A New Industrial Era Coming: Primary Dialogue on Evacuated Tube Transportation. Beijing: Tsinghai University Press. Sep. 2004. 
[2] Brad Swartzwelter. Faster Than Jets: A Solution to America's Long-term Transportation Problems. Alder Press, 2003.

[3] Daryl OSTER, Masayuki KUMADA, Yaoping ZHANG. Evacuated tube transport technologies

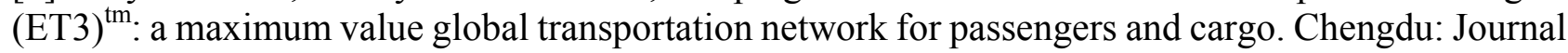
of Modern Transportation, 2011 Vol. 19 (1), p. 42-50

[4] Zhang Yaoping, Li Yanyan. Role and Position of ETT in The Future Comprehensive Transportation System. 2007 International Conference of Transportation Engineering Proceeding. The American Society of Civil Engineers, July 7, 2007, p.2796-2803

[5] Yaoping ZHANG, Daryl OSTER, Masayuki KUMADA, Jianye YU, Shengshan Li. Key Vacuum Technologies to Be Solved in Evacuated Tube Transportation. Chengdu: Journal of Modern Transportation, 2011 Vol. 19 (2), p.110-113

[6] Yaoping ZHANG. Numerical calculation and analyses on aerodynamic drag of subsonic train in evacuated tube transportation. Chengdu: Journal of Modern Transportation, 2012 Vol. 20 (1), p.44-48.

[7] Wu Ziniu. Aerodynamics (Part I). Beijing: Tsinghua University Press, 2007.4, p. 310-328

[8] Wang Xingyue. Aerodynamics Base. Xi'an: Northwestern Polytechnical University Press, 2006.5, p. 13

[9] Qian Yiji. Aerodynamics. Beijing University of Aeronautics \& Astronautics Press, 2004.9, p. 403 